\title{
Microstructure mapping in friction stir welds of 7449 aluminium alloy using SAXS
}

\author{
M. Dumont ${ }^{\text {a }}$, A. Steuwer ${ }^{\text {b }}$, A. Deschamps ${ }^{\text {c }}$, M. Peel ${ }^{\text {b }}$, P.J. Withers ${ }^{\text {b,* }}$ \\ a TECSEN-UMR 6122, Université P. Cézanne Aix-Marseille III, Faculté St-Jérôme, Case 261, Av. Escadrille Normandie-Niemen, \\ 13397 Marseille Cedex 20, France \\ ${ }^{\mathrm{b}}$ Manchester Materials Science Centre, University of Manchester, Grosvenor Street, Manchester M1 7HS, UK \\ ${ }^{\mathrm{c}}$ LTPCM/ENSEEG, UMR CNRS 5614, Domaine Universitaire, BP 75, 38402 St Martin d'Hères Cedex, France
}

\begin{abstract}
This paper describes the microstructural response of an age-hardenable, high-strength 7449 aluminium alloy to friction stir welding. Plates in the naturally aged (T3) and over-aged (T79) conditions were welded using two weld tool translation speeds. Maps of precipitate volume fraction and size were obtained by spatially resolved small-angle X-ray scattering over a cross-section of the welded plate, com-plemented by direct observations made by transmission electron microscopy. The spatial variations of precipitate volume fraction and size were assessed quantitatively for the characteristic zones of the welds, and supported by complementary hardness measurements. The effect of initial microstructure and welding speed, in particular in the heat-affected and thermomechanically affected zones, is discussed.
\end{abstract}

Keywords: Small-angle X-ray scattering; Synchrotron X-rays; Microstructure; Precipitation; 7xxx alloys

\section{Introduction}

Friction stir welding is a relatively novel and attractive process for joining aluminium alloys [1]. It is a solid-state process which avoids melting of the weld material. It can thus be used to join a large variety of alloys, in particular alloys generally considered difficult to weld by conventional techniques, such as age-hardenable alloys of the $2 \mathrm{xxx}(\mathrm{Al}-\mathrm{Cu}-\mathrm{Mg})$ and $7 \mathrm{xxx}(\mathrm{Al}-\mathrm{Zn}-\mathrm{Mg})$ series $[2,3]$. These alloys are frequently used in the aerospace industry and derive their excellent mechanical properties from strengthening precipitates developed by careful thermal ageing [4]. Although the weld material remains in the solid state throughout the joining process, it is exposed to a hightemperature excursion $[5,6]$ as well as undergoing high levels of deformation [7], leading to significant modification of the microstructure and mechanical properties [8-11] as well

\footnotetext{
* Corresponding author.

E-mail address: philip.withers@man.ac.uk (P.J. Withers).
}

as to the development of considerable levels of residual stress $[12,13]$.

For age-hardening alloys, the different high-temperature exposures and deformation paths characteristic of the weld and near-weld region are expected to have a profound effect on the magnitude and distribution of the hardening precipitates, depending on their nature, coherency, size and volume fraction. Accordingly, the following may occur:

- complete dissolution,

- partial dissolution and/or coarsening of existing precipitates,

- nucleation and growth of new precipitates.

This local evolution of microstructure leads to heterogeneous mechanical properties of the welded joint $[13,14]$. Qualitative studies of the resulting microstructure of the friction stir welding process using transmission electron microscopy (TEM) have already been published $[8,9]$, but 
to the authors' knowledge few quantitative studies on the precipitate distribution across the characteristic weld zones have been undertaken [15].

To this end, small-angle X-ray scattering (SAXS) appears to be a powerful technique. While the method has become a standard tool for the monitoring of precipitation, the capability of the synchrotron X-ray variant of the technique to provide spatial information has not really been explored. In this study, we have mapped experimentally the state of precipitation arising from friction stir welding in a quantitative and qualitative way by using both SAXS and TEM on a representative set of friction stir welds of the Al- $\mathrm{Zn}-\mathrm{Mg}-\mathrm{Cu}$ type (7449 alloy). Through the examination of four welds, we have studied the influence of the welding speeds and initial microstructure by comparing parent plates in two different tempers: one naturally aged (T3) containing Guinier-Preston (GP) zones with relatively low thermal stability and one over-aged (T79) containing primarily the equilibrium $\eta$-phase. These microstructural observations have been complemented by profiles of hardness across the welds.

\section{Materials and methods}

\subsection{Materials}

The alloy studied was the commercial high-strength 7449 alloy used for aerospace applications. It was supplied by Pechiney Rhenalu as $22 \mathrm{~mm}$ thick extruded plates in two different ageing conditions: T3 (naturally aged) and T79 (over-aged obtained by two-step ageing). This alloy (Al$8.4 \mathrm{Zn}-2.1 \mathrm{Mg}-1.8 \mathrm{Cu}-0.1 \mathrm{Zr}$ (wt.\%)) possesses one of the highest solute element contents of the high-strength $7 \mathrm{xxx}$ alloys $(\mathrm{HV}=190$ for the T79 temper and 170 for the T3 temper). Friction stir welding was carried out at TWI, UK. The as-received plates were first machined to reduce the thickness to $6.5 \mathrm{~mm}$ in the central region. Bead-on-plate welds were performed on single plates, with the translation direction corresponding to the extrusion direction. A weld tool rotation speed of $350 \mathrm{rpm}$ was used in all tests. Two different translation speeds were used: namely $175 \mathrm{~mm} / \mathrm{min}$ (designated as "low speed") and $350 \mathrm{~mm} / \mathrm{min}$ (designated as "high speed"). The tool shoulder measured $23 \mathrm{~mm}$ in diameter and the tool pin $8 \mathrm{~mm}$ in diameter.

\subsection{Microstructural characterisation}

\subsubsection{Optical microscopy}

Optical microscopy was used to characterise the grain and subgrain structure of the alloys in the different regions of the welded plate. The microstructure was examined on the plane normal to the weld direction. The grain structure was revealed by electropolishing in $5 \% \mathrm{HBF}_{4}$ at $28 \mathrm{~V}$ for $2 \mathrm{~min}$. Subgrain boundaries were delineated by chemical chromic etching $\left(1 \mathrm{ml} \mathrm{HF}+16 \mathrm{ml} \mathrm{HNO}_{3}+84 \mathrm{ml}\right.$ chromic solution composed of $3 \mathrm{mg}$ crystallised chromic anhydrite in distilled water).

\subsubsection{TEM}

Imaging of fine-scale precipitation (strengthening precipitation) was undertaken by TEM with a Jeol 2010 microscope, operating at $200 \mathrm{kV}$. Samples were prepared by double-jet electropolishing using a solution composed of $1 / 3$ nitric acid and $2 / 3$ methanol. Polishing conditions were $-25^{\circ} \mathrm{C}$ and $11 \mathrm{~V}$.

\subsection{3. $S A X S$}

SAXS has proved to be a powerful technique for studying precipitation, especially for $\mathrm{Al}-\mathrm{Zn}-\mathrm{Mg}$ alloys [16-23]. In particular, average features of the precipitate microstructure, such as the mean radius of the particles and their volume fraction, can be evaluated non-destructively. All SAXS experiments presented here were carried out on the D2AM beamline (BM02-CRG) of the European synchrotron radiation facility (ESRF). X-rays generated by a bending magnet are focused and monochromated to better than $\delta \lambda / \lambda=2 \times 10^{-4}$ at a wavelength of $1.48 \AA$. The SAXS patterns were acquired using a two-dimensional CCD camera. Depending on the initial state of the material (containing small GP zones (T3) or large $\eta$ particles (T79)), two sample-to-detector distances were used, covering in total a range of scattering vectors $[0.001,0.7] \AA^{-1}$, corresponding to precipitate radii ranging from of the order of angstroms to $20 \mathrm{~nm}$. Data files were corrected for electronic noise, the flat field of the detector, and background noise. A circular average was taken around the transmitted beam to obtain the intensity as a function of scattering angle. The scattered intensity was finally converted into absolute values, $I$, using a reference sample and the measurement of the intensity of the direct beam through calibrated filters. Scattering curves of $I$ versus $q$ obtained for the two initial states T3 and T79 are displayed in Fig. 1(a).

The precipitate size was evaluated using the Guinier approximation (for $1.2 R_{\mathrm{g}}<q<2.8 R_{\mathrm{g}}$ ), which provides the gyration radius $R_{\mathrm{g}}$ of the particles:

$I \propto \exp \left(-\frac{q^{2} R_{\mathrm{g}}^{2}}{3}\right)$

where $q$ is the scattering vector $\left(\AA^{-1}\right)$. In practice, the Guinier radius is estimated from the slope of the $\ln (I)$ versus $q^{2}$ plot, as illustrated in Fig. 1(b), for the T3 and T79 states. A previous comparison with TEM observations has shown that for the $\mathrm{Al}-\mathrm{Zn}-\mathrm{Mg}$ system, at least for $\eta^{\prime}$ and $\eta$ particles, the Guinier radius is very close to the mean radius of the precipitates [23]. Therefore in the following the Guinier radius will be taken to represent a direct measure of precipitate mean radius with no distinction between $\eta^{\prime}$ and $\eta$ particles.

The precipitate volume fraction $f_{\mathrm{v}}$ was evaluated using the measured integrated intensity $Q_{0}$ :

$Q_{0}=\int_{0}^{\infty} I(q) q^{2} \mathrm{~d} q=2 \pi^{2}(\Delta \rho)^{2} f_{\mathrm{v}}\left(1-f_{\mathrm{v}}\right)$

where $\Delta \rho$ is the electron density contrast between the precipitate and matrix [24]. The determination of this 


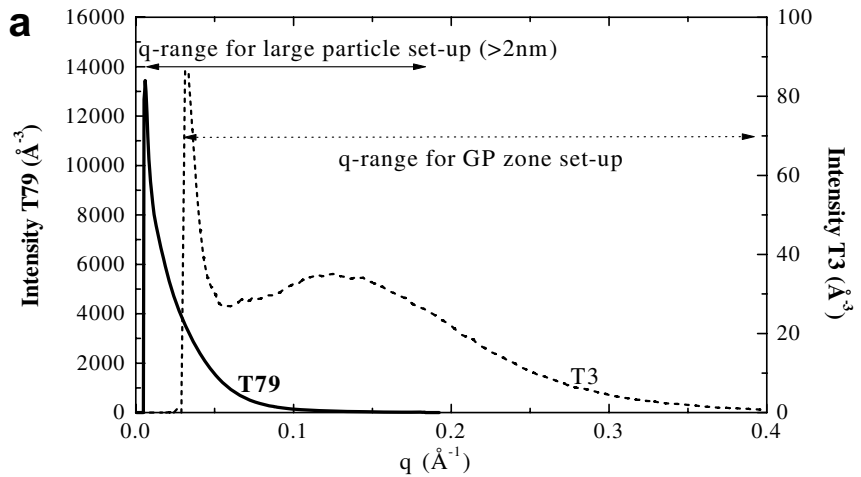

b

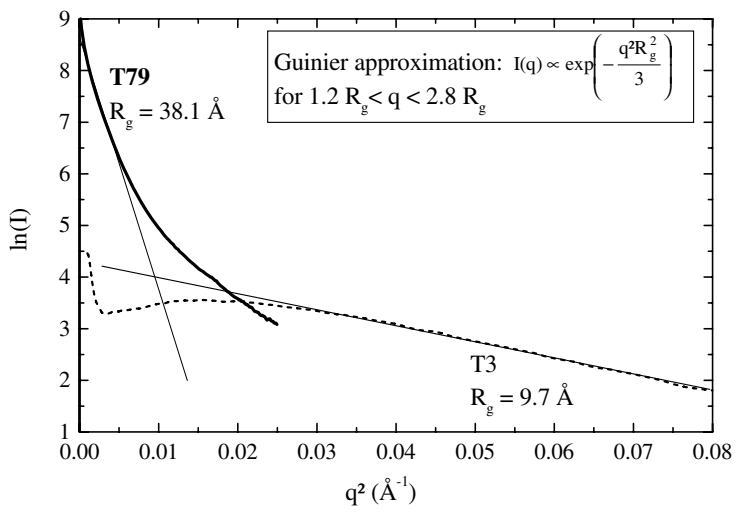

C

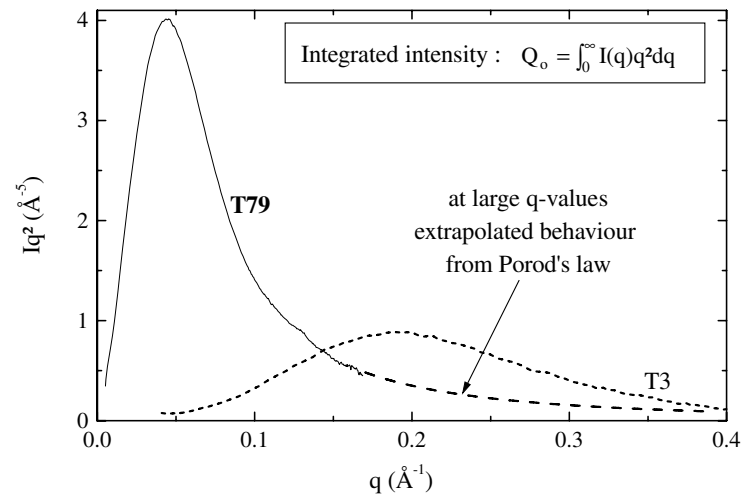

Fig. 1. Typical SAXS spectra for the parent T3 and T79 materials. (a) $I$ vs. $q$ plot (note the different scales used for the two curves). (b) $\ln (I)$ vs. $q^{2}$ Guinier plot. (c) $I q^{2}$ vs. $q$ plot to determine the integrated intensity $Q_{o}$.

parameter requires knowledge of the precipitate composition. In a previous study [23], a $\mathrm{Zn} /(\mathrm{Mg}+\mathrm{Al})$ ratio of 1.2 inside the precipitates was determined by both TEM and tomographic atom probe for both $\eta^{\prime}$ and $\eta$ precipitates. This ratio is used throughout this paper to infer the precipitate volume fraction. A more complete description of the calibration procedure for particle radius and volume fraction is published elsewhere [23].

\subsection{Microhardness}

The hardness of the weld region was mapped using Vickers microindentation with a $500 \mathrm{~g}$ load. Profiles of hardness were made on sections perpendicular to the welding direction as a function of distance from the weld line.

\section{Results}

\subsection{Grain structure}

Irrespective of heat treatment condition, the grain structure in the parent plates comprises a pancake morphology characteristic of extruded plates. The extent of the grains is around $500 \mu \mathrm{m}$ with aspect ratios between 5 and 10 (grains elongated in the extrusion direction), whereas the welldefined subgrain structure has a characteristic size of around $10-20 \mu \mathrm{m}$.

The effect of friction stir welding on the grain structure is illustrated in Fig. 2. In the nugget (Fig. 2(c)), very fine grains $(\sim 10 \mu \mathrm{m})$ have formed by recrystallisation. Some bands of smaller recrystallised grains can also be observed (grey regions on the micrograph). These regions are more numerous at the higher welding speed. In the thermomechanically affected zone (TMAZ) (Fig. 2(a), (b) and 2(d)), the material flow produced by welding can be observed. Moreover, this upwards movement (i.e. towards the tool contact surface) of material is much more pronounced on the advancing side than on the retreating side.

\section{2. $S A X S$ results}

The SAXS measurements performed on the various welds are displayed in Fig. 3 as cross-sectional maps of inferred volume fraction and mean radius for all four welded plates. No major differences concerning the characteristics of the precipitates have been found between the advancing and the retreating side. The characteristic shape of the weld nugget and the through-thickness variations can be observed.

The characteristic zones associated with friction stir welds are delineated by changes in the precipitate volume fractions, as illustrated in Fig. 4(a) for the T79 plate. T79 is initially constituted of stable $\eta$ precipitates with the TMAZ divided into two subzones, as proposed previously [9]. In essence the weld microstructure can be categorised as:

- HAZ (heat-affected zone): characterised by a gradual drop in precipitate volume fraction due to the high temperature exposure, leading to the partial dissolution of hardening precipitates, without significant change in the particle size (see Fig. 4(b)).

- $T M A Z(I)$ : the decrease in precipitate volume fraction that occurs in the HAZ stops, possibly even increasing slightly.

- TMAZ (II): is characterised by the decrease of the volume fraction down to zero as the peak temperature approaches the solvus temperature of the precipitation phase.

- Nugget: none of the original $\eta$ precipitates have survived in the nugget, although some new precipitates have formed. The presence of new smaller precipitates is also evidenced by a recovery in hardness (Fig. 7); these 
(a) TMAZ, retreating side

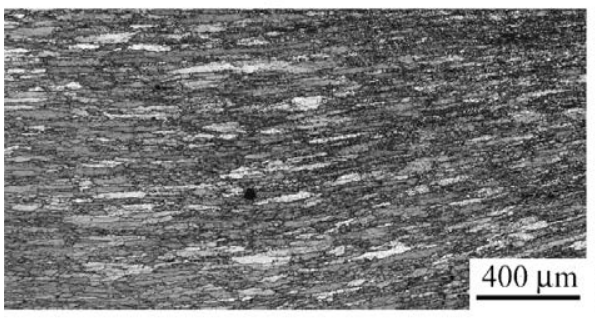

retreating side (b) TMAZ, advancing side

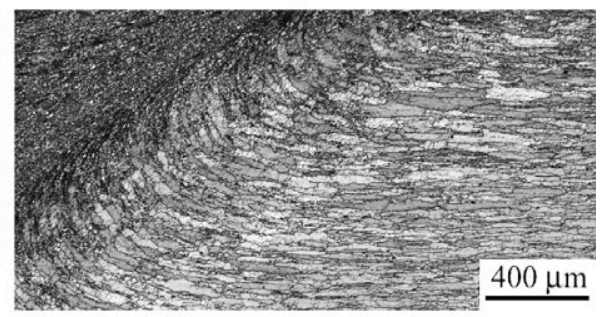

advancing side

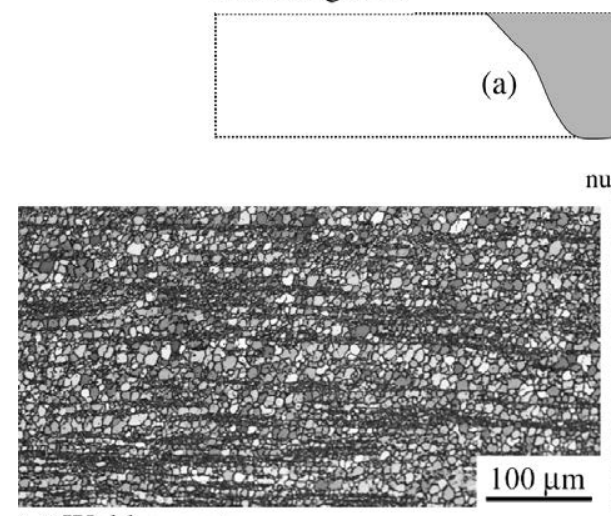

(c) Weld nugget

(c)

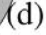

TMAZ TMAZ

(II) (I) HAZ

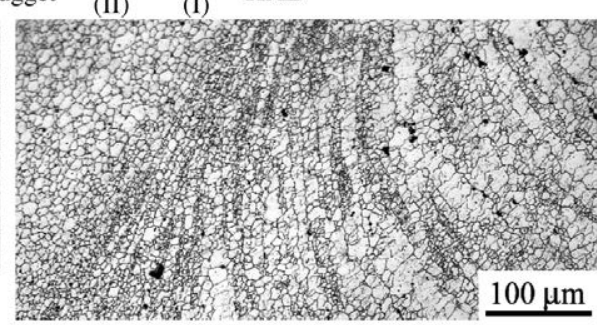

(d) TMAZ, advancing side

Fig. 2. Grain structure of low-speed welds (essentially identical for T3 and T79 welds) and a schematic showing the extent of the HAZ, TMAZ (I and II) and nugget, as well as appropriate location of images (a), (b), (c) and (d).

are GP zones that formed during the low-temperature regime of the welding process and which have continued to grow during subsequent natural ageing.

The variation in GP zones in the nugget of the T79 plate was also determined by SAXS using the set-up optimised for small particles (see Section 2.2.3). Their size was estimated to be $9 \AA$ and their volume fraction around $4 \%$ if the $(\mathrm{Zn}+\mathrm{Cu}) /(\mathrm{Al}+\mathrm{Mg})$ ratio of 1.2 is applied. This is comparable to that for the initial T3 plate material (see Fig. 1(c)), i.e. as would occur after natural aging.

In the $\mathrm{T} 3$ welded plates, new precipitates have formed during the welding process as a consequence of the hightemperature excursion (Fig. 4). Regarding their size, they are presumably of a stable nature, i.e. of $\eta$ phase. GP zones are evident inside the nugget having characteristic sizes below $1 \mathrm{~nm}$. Moreover, GP zones remaining from the parent material are observed at distances greater than $18 \mathrm{~mm}$ from the centreline in the low-speed weld. As shown in Fig. 4 in the HAZ these coexist with newly formed $\eta$ precipitates. This coexistence is illustrated in Fig. 5 which shows the scattering curve ( $I q^{2}$ versus $q$ plot) for the T3 low-speed weld at a distance of $18 \mathrm{~mm}$ from the weld line. Two maxima can be observed corresponding to the two families of precipitates, the one at lower $q$-values representative of the $\eta$ particles and the one at large $q$-values representative of the GP zones.

The influence of the welding speed and of the initial state is discussed in Section 4.

\subsection{TEM observations}

TEM images of the strengthening precipitates in the T79 low-speed weld are shown in Fig. 6. As stated previously, the initial state of the parent plate mainly comprises $\eta$ precipitates. However, some evidence (see associated diffraction pattern) points to the coexistence of $\eta^{\prime}$ precipitates. These metastable semi-coherent plate-like precipitates have already been observed in over-aged tempers [23]. They have been found to be close in composition and size to the coexisting $\eta$ precipitates. Since $\eta$ and $\eta^{\prime}$ are of comparable size and composition, it is not important from a strengthening viewpoint that SAXS cannot differentiate between these phases.

In the HAZ identified by SAXS $(x=20 \mathrm{~mm})$, no appreciable modification in the precipitate microstructure can be discerned from TEM observations. This is consistent with the fact that only the volume fraction of precipitates (difficult to estimate by TEM) is affected and not their mean size. However in the TMAZ, it is evident that the precipitate microstructure evolves markedly, leading to coarsening of the precipitates and a decreasing volume fraction, in accordance with SAXS. In addition no evidence of high dislocation densities or dislocation-precipitate interactions was found in the TMAZ $(x=12 \mathrm{~mm})$. Close to the nugget, large hexagonal plate-like particles $(\sim 50 \mathrm{~nm}$ in diameter, $\sim 15 \mathrm{~nm}$ in thickness) are observed in Fig. 6, some lying flat, some lying edge-on on (111)Al planes.

Moreover, the associated diffraction patterns reveal the evolution of the nature of the precipitates. In the HAZ, 


\section{T3 welds}

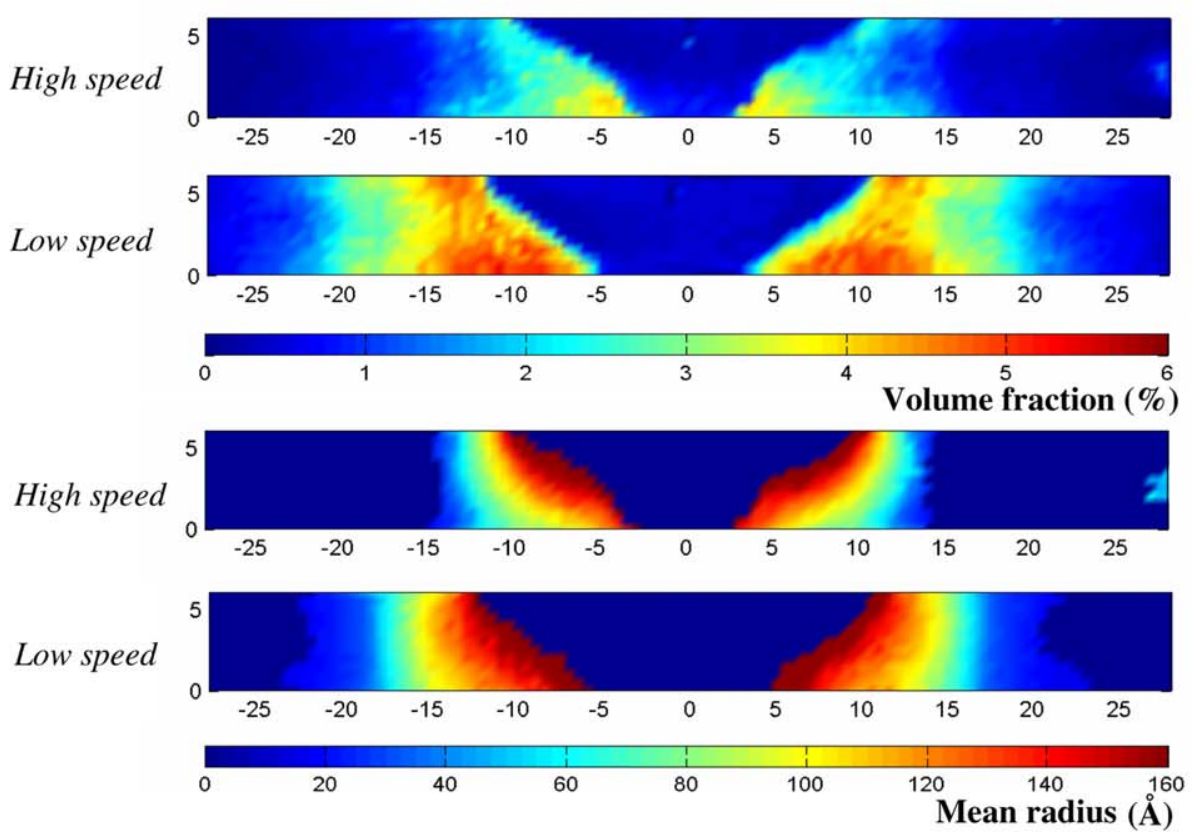

\section{T79 welds}
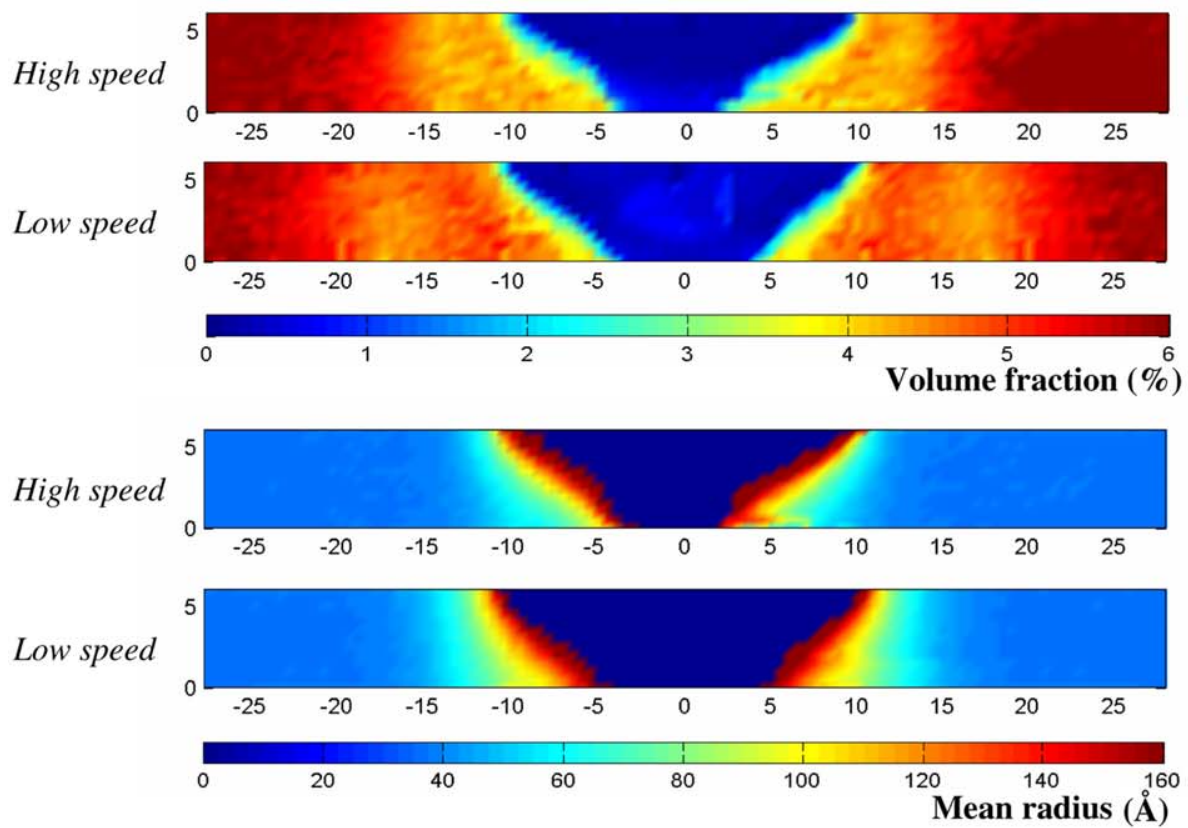

Fig. 3. SAXS maps (volume fraction and size) of $\eta$ precipitates for the T3 and T79 welds under high and low welding speeds. Note that the friction stir welding tool shoulder diameter was $23 \mathrm{~mm}$.

$\eta^{\prime}$ and $\eta$ precipitates are still present, whereas in the TMAZ diffraction spots arising from $\eta^{\prime}$ precipitates have disappeared. In fact the less stable $\eta^{\prime}$ phase and small $\eta$ precipitates are expected to be the first to dissolve whereas larger $\eta$ precipitates will tend to coarsen and lead to the hexagonal plates observed in the nugget/TMAZ boundary $(x=8 \mathrm{~mm})$. In the nugget, a small number of coarse particles can be observed and the associated diffraction pattern on the $[100]_{\mathrm{Al}}$ zone axis reveals the presence of GP zones.

\subsection{Microhardness}

Fig. 7 shows the results of microhardness measurements performed over the weld cross sections for the T3 and T79 welds in the high- and low-speed conditions. Unsurprisingly, the hardness of the parent plate in the T3 condition ( $\mathrm{HV} \sim 170)$ is lower than for T79 (HV 190). For both T3 and T79 welds, the high-temperature exposure in the near-weld zone leads to a loss in microhardness. Although 
a

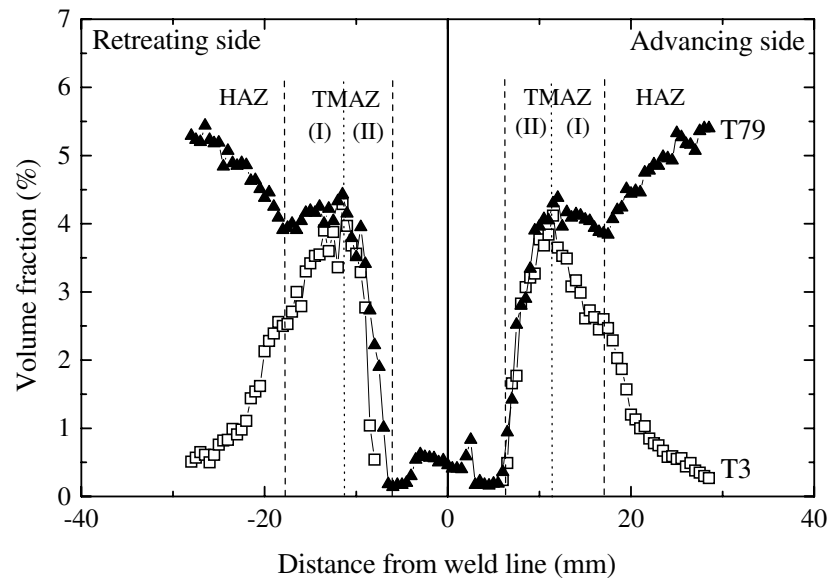

b

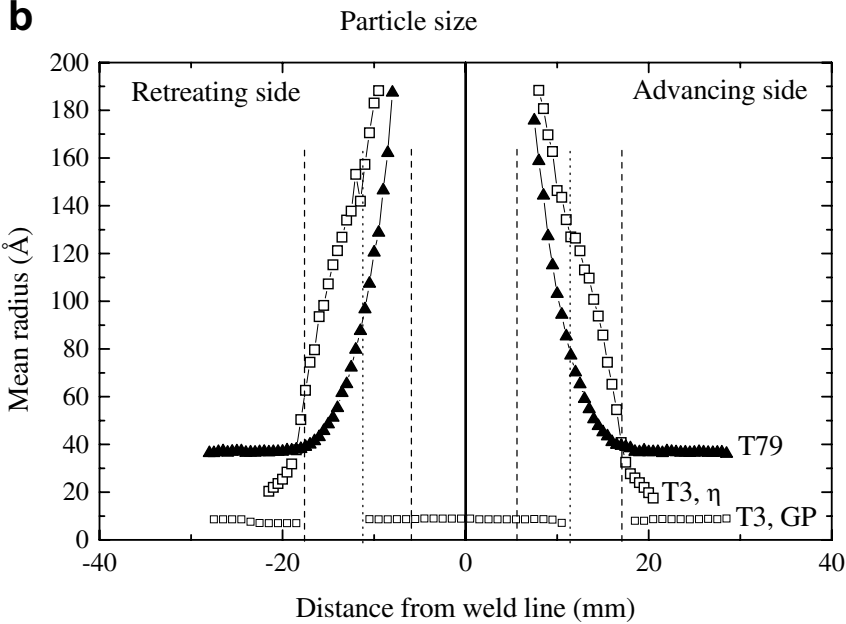

Fig. 4. Evolution of (a) the volume fraction of the $\eta$ precipitates and (b) mean radius of $\eta$ precipitates and GP zones across the various characteristic zones of a friction stir weld (T79 and T3 low-speed welds at mid-plate) as determined by SAXS. Note that volume fraction of GP zones is not shown because of the lack of reliability of the calibration due to compositional uncertainty in the GP zones.

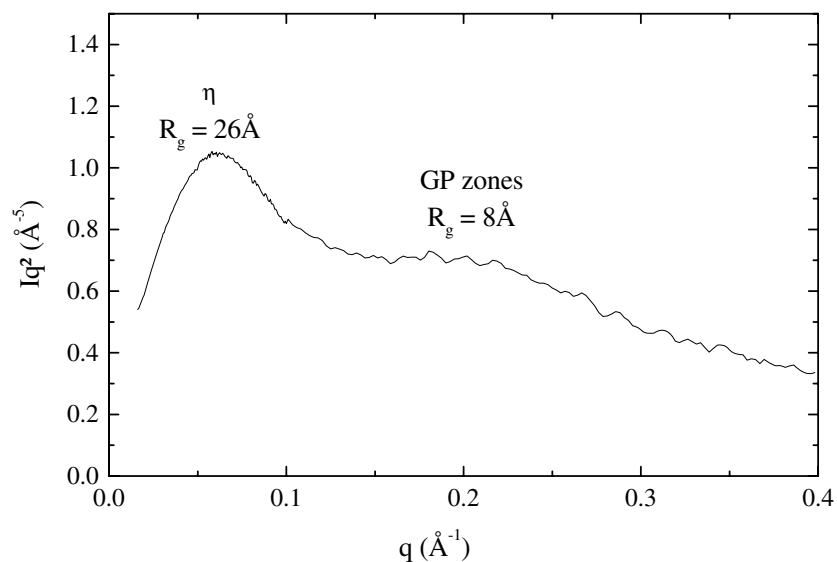

Fig. 5. Scattering curve as $I q^{2}$ vs. $q$ plot as measured for the T3 low-speed weld recorded $18 \mathrm{~mm}$ from the weld line in the middle of the plate. This plot confirms the coexistence of GP zones and stable ( $\eta$ and $\left.\eta^{\prime}\right)$ precipitates in the HAZ.
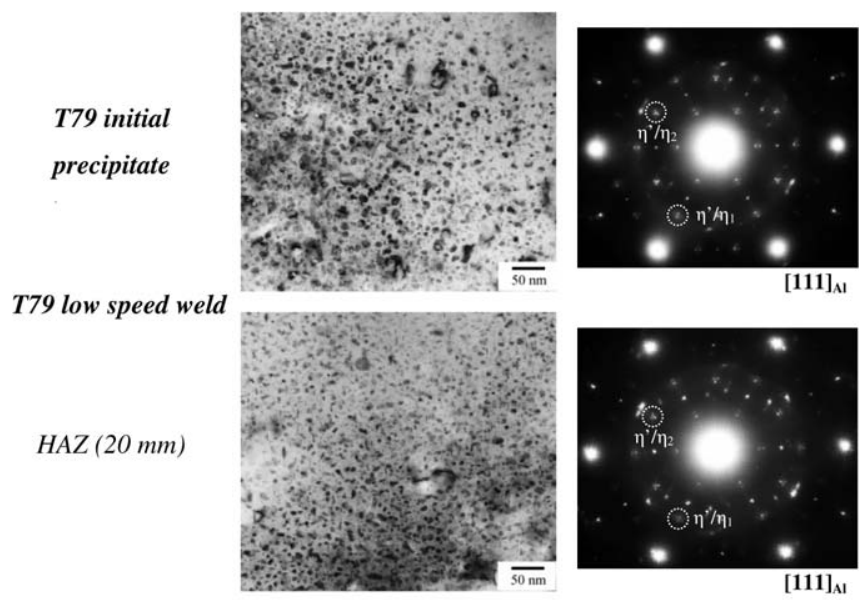

$\operatorname{TMAZ}(I)$
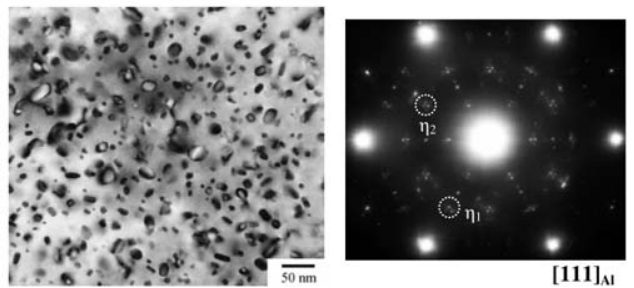

TMAZ (II)
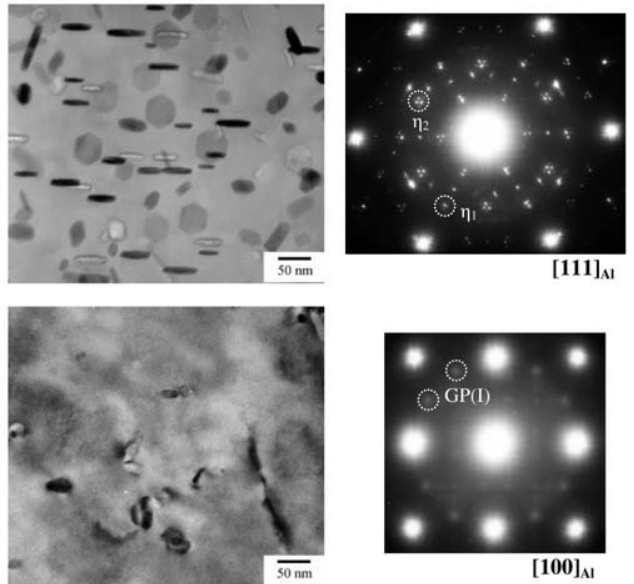

Fig. 6. TEM micrographs of precipitates in the different regions of the T79 low-speed weld. Bright-field images were taken in (1111) 1$)_{\mathrm{Al}}$ two-beam conditions close to a $\left[\begin{array}{llll}1 & 1 & 0\end{array}\right]_{\mathrm{Al}}$ zone axis.

complete dissolution occurs in the nugget region, it recovers some hardness upon cooling and natural ageing. During this period, GP zones nucleate and grow in regions where supersaturation is sufficient. This is particularly the case in the nugget and the TMAZ (II) (Fig. 4(b)).

In TMAZ (I) of the T79 welds the volume fraction of surviving precipitates is large enough to inhibit nucleation of GP zones. The critical volume fraction of $3.5-4 \%$ is obtained from Fig. 4. This critical value determines the remaining solute atoms available in the matrix. GP zone formation is only possible once the remaining solute is high enough. It is possible to quantify this critical solute level through the knowledge of the volume fraction and the composition of coarse precipitates. This can be estimated using a mass balance. Moreover, these coarse precipitates are unable to strengthen the material, leading to a 

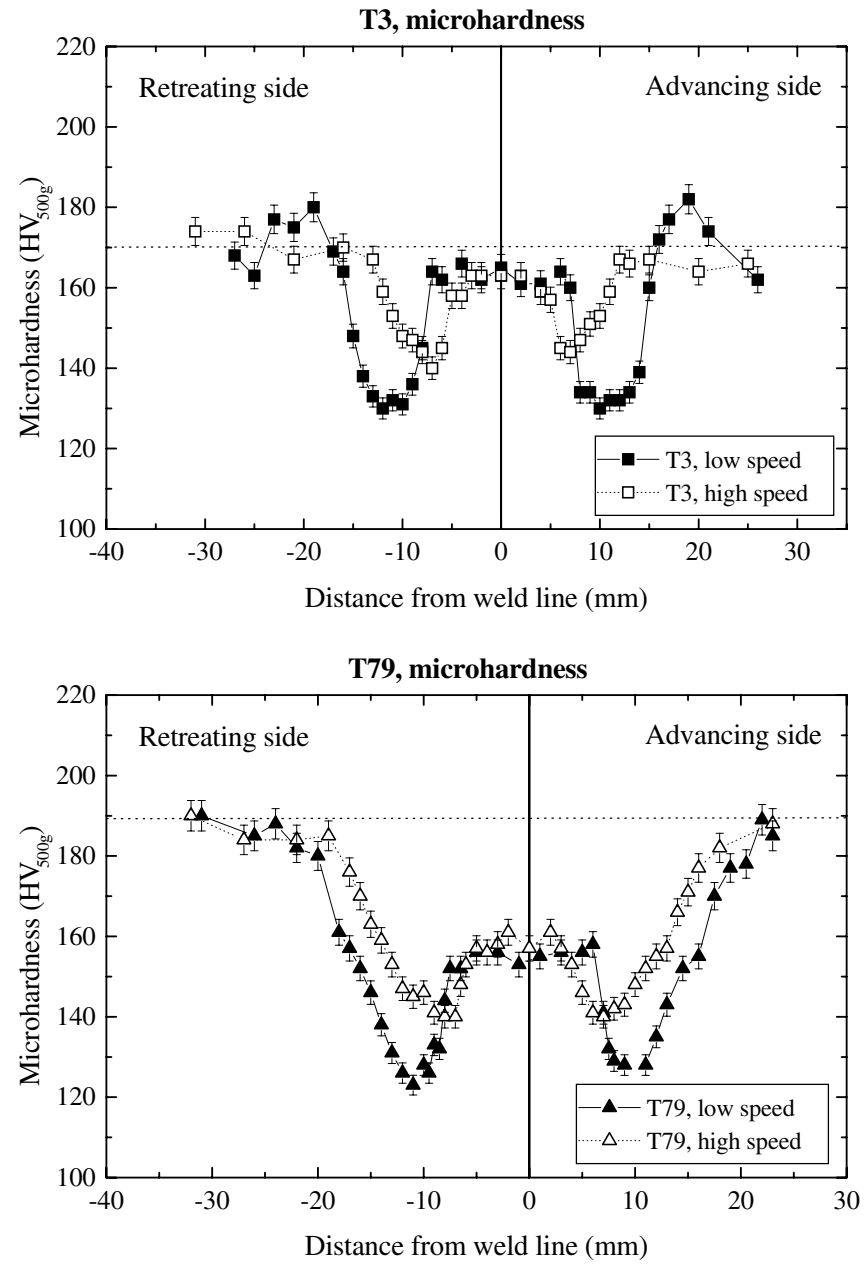

Fig. 7. Microhardness profiles across the mid-plate thickness of (a) T3 and (b) T79 welds for the low and high welding speeds.

minimum of hardness at the transition between TMAZ (I) and (II).

In the T3 welds, the hardness is lower in the TMAZ compared with the initial T3 hardness level. In fact the newly formed precipitates are not significantly strengthening due to their size. However, in the region located around $\pm 18 \mathrm{~mm}$ from the centre line of the weld, the conditions of nucleation and growth of these stable precipitates are such that they can provide some hardening in addition to remaining GP zones, so that the weld has a higher hardness than the original plate.

\section{Discussion}

\subsection{Effect of the welding parameters on the microstructural evolution}

Fig. 3 shows that by decreasing the welding speed, the major difference is the widening of the nugget, HAZ and TMAZ, irrespective of the initial temper. The region of the nugget corresponds well with the diameter of the tool shoulder on the top surface contracting to a diameter of around $5 \mathrm{~mm}$ for the high-speed welds and $10 \mathrm{~mm}$ for the low-speed welds near the bottom surface. This is in line with the greater heat input [2] for the low-speed welds. For a given tool rotation rate a higher welding speed results in a lower heat input to the plate. Two major effects derive from this: firstly, the region over which the peak temperature exceeds $150{ }^{\circ} \mathrm{C}$ is narrower; secondly, for a given peak temperature, time spent at high temperature is shorter. Therefore for the high welding speed the affected region is narrower due to the former effect and as a consequence of the latter the coarsening (increase of the mean radius) is less significant. It is also clear from Fig. 3 that the pin plays a relatively weak role in determining the profile of the microstructure, i.e. the extent of the recrystallised nugget and HAZ which are much broader than the pin diameter and do not reflect its profile. This is corroborated by the results of Woo et al. [25] which show the field of influence of the weld extends slightly beyond the shoulder of the tool irrespective of whether there is a pin or not.

\subsection{Effect of the initial state on the microstructural evolution}

We discuss the influence of the initial state by comparing T3 and T79 welds (see Figs. 3 and 4), particularly the lowspeed welds, in the different characteristic zones. Note that the definition of these regions is based on the T79 welds and will be used for the T3 welds by extension supported by the fact that both welds have experienced essentially the same thermal history and deformation path.

\subsection{1. $H A Z$}

This region is characterised by a drop in the volume fraction of the precipitates, as observed for the T79 weld. This is accompanied by a slight decrease in hardness, not drastic because the remaining precipitates are still strengthening. It is perhaps surprising to note from Fig. 4 that dissolution first occurs at essentially constant mean radius in the HAZ. This phenomenon has been observed in previous experiments (e.g. [17]). During heat input, dissolution and coarsening are competing phenomena. In accordance with this, Nicolas and Deschamps [22] have shown using nonisothermal heat treatments that dissolution happens first and is characterised by a decreasing volume fraction and a relatively constant mean radius. To understand why the mean radius remains essentially constant in the dissolution regime, it should be remembered that SAXS samples a distribution of particle sizes. Nicolas and Deschamps explain this in terms of the critical radius. For a given solute content this increases with temperature and decreases as the solute content increases. When submitted to a sudden input of heat, therefore, the critical radius $r^{*}$ increases significantly becoming larger than all the existing particles. As a result all the particles begin to dissolve but the dissolution rate is higher for small particles than for big particles. This means that dissolution affects all particles but with only a small variation in the mean radius. In other words, the particle size distribution is decreasing, but without a significant shift in the mean value. Only when sufficient solute atoms 
have been returned to solution can the critical radius decrease and then the coarsening regime can begin: dissolution of smaller particles accompanied by growth of the biggest ones. As a consequence, in the HAZ, the dissolution regime is dominant and the time at high temperatures is too short to allow coarsening to occur.

In the T3 material, in the same region, GP zones are expected to have dissolved during the welding process, bearing in mind that the temperature peak must have exceeded $150{ }^{\circ} \mathrm{C}$ in order to have affected the T79 weld. However, the GP zone microstructure has the potential to recover during natural ageing, as also observed in the nugget. Around $\pm 20 \mathrm{~mm}$, the thermal conditions are met to nucleate new precipitates in the T3 low-speed weld (Fig. 4(b)), even leading to a slightly improved hardness relative to the base $\mathrm{T} 3$ material, considering the size and volume fraction of the formed precipitates.

\subsubsection{TMAZ (I)}

In the low-speed T79 weld, a slight recovery in the volume fraction is observed (see Figs. 3 and 4). This phenomenon is generally attributed to the interaction between the extensive deformation experienced during friction stir welding and the precipitation $[8,9]$. It has been proposed that this interaction leads to the nucleation of new precipitates on dislocations [9]. Additionally one might speculate that the dislocations generated during the welding process will favour a faster diffusion through the cores of the dislocations leading to a faster recovery of the volume fraction in this region, as compared to the HAZ. These mechanisms must be regarded as speculative at present because to date TEM has not revealed any direct evidence of an interaction between dislocations and precipitates. However, the dislocations may well have partially recovered during the thermal cycle or subsequently have been annealed during foil preparation.

Comparing the T3 and T79 welds (see Fig. 4), it can be seen that the material initially in the T3 condition leads to bigger precipitate sizes than the T79 condition accompanied by a lower volume fraction. Different hypotheses can be drawn considering that the dominant mechanisms in the T79 weld are growth/coarsening of pre-existing precipitates whereas for T3 material the first stage is the dissolution of the initial GP zones, followed by the nucleation/ growth and coarsening of new stable precipitates:

- Regarding the thermal cycle experienced in the TMAZ the heating rates/cooling rates are marked $\left(\sim 50^{\circ} \mathrm{C} / \mathrm{s}\right)$ with peak temperatures around $450-530^{\circ} \mathrm{C}$ beneath the tool $[26,27]$. As a result the GP zones have probably already dissolved before the nucleation of new precipitates begins. This nucleation may occur at high temperatures $\left(>200^{\circ} \mathrm{C}\right)$. This means that the radius of the nuclei, close to the critical radius $r *$, is expected to be larger than the original $\eta$ precipitates in the T79 base material.

- Moreover, the driving force for growth will be higher in the T3 material than in the T79 weld. This is supported by the lower volume fraction of precipitates achieved at the end of the process in this region (see Fig. 4). As the driving force for growth is directly related to the difference between the mean concentration in solute atoms in the matrix and the equilibrium concentration, the higher the volume fraction of precipitates, the closer to the equilibrium volume fraction, the smaller the driving force.

\subsubsection{TMAZ (II)}

Both the volume fraction and mean size of the precipitates in the T3 and T79 welds are very similar (see Fig. 4), even if the T3 material still shows slightly coarser particles. This is consistent with the previous hypotheses considering nucleation temperature and driving force for growth. In fact the driving force for growth is now equivalent in both materials but the nucleated precipitates in the T3 material are slightly bigger than the T79 initial precipitates, this difference in size remains up to the end of the process.

\subsubsection{Nugget}

The boundary of the nugget matches both the extent of the recrystallised domain (see Fig. 2) and the extent of the complete disappearance of coarse precipitates (see Fig. 3) in both low- and high-speed welds. This suggests that recrystallisation can only take place once all coarse precipitates have disappeared, i.e. for peak temperatures exceeding the solvus temperature of the $\eta$ phase. Differential scanning calorimetry (DSC) performed on this material at $20 \mathrm{~K} / \mathrm{min}$ shows that dissolution is completed at temperatures higher than $475^{\circ} \mathrm{C}$. Clearly, this heating rate is much less than that experienced at the nugget boundary (modelling suggests around $10-50 \%$ ). Therefore the temperature for complete dissolution is expected to be higher than the one estimated directly by DSC. Some simple arguments might support the idea that the recrystallisation boundary matches the location of complete precipitate dissolution. Firstly, material flow is easier in soft regions. If some precipitates remain, the yield stress may be large enough to inhibit mixing. As a result, a high level of dissolution of the strengthening precipitates may be necessary with the consequence that the nugget boundary will close to the solvus temperature. Secondly, recrystallisation is very difficult in the presence of small particles which may pin the grain boundaries. As a result, complete dissolution may be a necessary condition within the nugget boundary. Thus we could consider this temperature as a preliminary estimate (lower limit) for the peak temperature attained at the nugget boundary, since the temperature might be higher than the solvus temperature at the nugget boundary (low deformation, high heat input).

\section{Conclusions}

In this study, complementary techniques, including nondestructive evaluation by high energy synchrotron X-rays, direct observation by TEM and hardness measurements, 
were applied to map the spatial variation of the precipitation and to obtain a better understanding of the processes taking place during the complex thermomechanical process of friction stir welding. The following major conclusions can be drawn:

(i) SAXS can provide very detailed maps in cases where the SAXS signals can be unambiguously interpreted. For AA7449 the microstructurally similar $\eta$ and $\eta^{\prime}$ can be separated from the competing GP distribution. In our case the maps show the correlation between the distribution of heat input across the welds and the consequent precipitate microstructures.

(ii) The response of the base material to friction stir welding includes all the stages of precipitate evolution: dissolution, growth, coarsening and even nucleation of new phases. Coarsening is the most detrimental effect as it prevents the material from recovering its mechanical properties, either by natural ageing or by post-weld heat treatments. In particular, it may be most detrimental to weld base material in the naturally aged temper, initially containing GP zones. This is especially vulnerable to changes in temperature due to the low stability of GP zones because coarse $\eta$ precipitates can form.

(iii) The welding speed (which determines the heat generation per unit time and welded length) is a key factor in controlling the extent of the precipitate evolution irrespective of the initial state (T3 or T79). As shown by Reynolds et al. [26] it affects the peak temperature but also the temperature gradient. In this respect a lower welding speed will favour coarsening and a broader microstructurally affected zone.

(iv) The extreme deformation in the TMAZ and nugget may have a secondary affect on the kinetics of precipitate evolution.

\section{Acknowledgements}

We are grateful to Pechiney-Rhenalu and Pechiney-UK for providing the materials and to TWI for performing friction stir welding, as well as H.R. Shercliff and P. Colegrove of Cambridge University. F. Bley, as well as all the staff of D2AM/ESRF, are gratefully acknowledged for help with the SAXS experiments. Furthermore we thank the ESRF for the access to the synchrotron X-ray radiation through proposal ME-630. A.S. thanks the FaME38 facility for hospitality. P.W. acknowledges the support of a Royal Society-Wolfson Merit Award.

\section{References}

[1] Thomas WM, Nicholas ED, Needham JC, Murch MG, TempleSmith P, Dawes CJ. International Patent PCT/GB92/02203, GB Patent 9125978.8; 1991, US Patent 5,460,317 1995.

[2] Heinz A, Haszler A, Keidel C, Moldenhauer S, Benedictus R, Miller WS. Mater Sci Eng A 2000;A280:102-7.

[3] William SW. Air Space Eur 2001;3:64-6.

[4] Löffler H, Kovács I, Lendvai J. J Mater Sci 1983;18:2215-40.

[5] Chen CM, Kovacevic R. Int J Mach Tools Manufact 2003;43:1319-26.

[6] Song M, Kovacevic R. Int J Mach Tools Manufact 2003;43:605-15.

[7] Li Y, Murr LE, McClure JC. Mater Sci Eng A 1999;A271:213-23.

[8] Rhodes CG, Mahoney MW, Bingel WH. Scr Mater 1997;36:69-75.

[9] $\mathrm{Su}$ JQ, Nelson TW, Mishra R, Mahoney M. Acta Mater 2003:51713-29.

[10] Fonda RW, Bingert JF, Colligan KJ. Scr Mater 2004;51:243-8.

[11] Staron P, Koçak M, Williams S, Wescott A. Physica B 2004;350:E491-3.

[12] Sutton MA, Reynolds AP, Wang DQ, Hubbard CR. J Eng Mater Technol 2002;124:215.

[13] Peel M, Steuwer A, Preuss M, Withers PJ. Acta Mater 2003;51:4791-801.

[14] Ehrström JC, Bigot A, Cervi L, Gérard H. Mater Sci Forum 2003;426-432:2941-6.

[15] Genevois C, Deschamps A, Denquin A, Doisneau-Cottignies B. Acta Mater 2005;53:2447-58.

[16] Radomsky M, Kabish O, Löffler H, Lendvai J, Ungár T, Kovács I, et al. J Mater Sci 1979;14:2906-12.

[17] Gueffroy B, Löffler H. Phys Stat Sol (a) 1981;66:585-90.

[18] Gomiero P, Reeves A, Pierre A, Bley F, Livet F, Vichery H. In: Proceedings of fourth conference on aluminum alloys: their physical and mechanical properties, 11-16 Sept 1994, Atlanta, GA, vol. 1. 1994. p. 644-51.

[19] Werenskiold JC, Deschamps A, Bréchet Y. Mater Sci Eng A 2000;A293:267-74.

[20] Zheng LJ, Chen CQ, Bai PC, Zhou TT, Liu PY, Dong BZ. Mater Lett 2003;58:25-8.

[21] Nicolas M, Deschamps A. Metall Mater Trans A 2004;35A:1437-48.

[22] Nicolas M, Deschamps A. Acta Mater 2003;51:6077-94.

[23] Dumont M, Lefebvre W, Doisneau-Cottignies B, Deschamps A. Acta Mater 2005;53:2881-92.

[24] Deschamps A, Bréchet Y, Livet F. Mater Sci Technol 1999;15:993-1000.

[25] Woo W, Choo H, Brown DW, Bourke MAM, Feng Z, David SA, et al. Appl Phys Lett 2005;86:231902.

[26] Reynolds AP, Tang W, Khandkar Z, Khan JA, Lindner K. Sci Technol Weld Join 2005;10:190-9.

[27] Peel MJ, Steuwer A, Withers PJ, Dickerson T, Shi Q, Shercliff H. Metall Trans 2006;37A:2183-93. 